\title{
Constitution of Design Management System for Curtain Wall
}

\author{
Hong-Kyoon Lim \\ Dept. of Architectural Engineering Master's course \\ Dankook University \\ Hannam-dong, Yongsan-gu, Seoul, Korea
}

\author{
Sang-Ho Yoon \\ Dept. of Architectural Engineering Master's course \\ Dankook University \\ Hannam-dong, Yongsan-gu, Seoul, Korea
}

\author{
Sang-Woo Park \\ Dept. of Architectural Engineering Master \\ Dankook University \\ Hannam-dong, Yongsan-gu, Seoul, Korea \\ Jae-Youl Chun \\ Dept. of Architectural Engineering Professor \\ Dankook University \\ Hannam-dong, Yongsan-gu, Seoul, Korea
}

\author{
Sang-Jun Park \\ Dept. of Architectural Engineering Ph.D \\ Dankook University \\ Hannam-dong, Yongsan-gu, Seoul, Korea
}

\begin{abstract}
The curtain wall design process of Korea can be mainly divided into Basic DWG phase performed in architectural design phase and Shop DWG phase performed in the curtain wall design phase. The designing in such process (the process of going over to Shop from Basic) is being performed mainly by the outcome. So it is difficult to communicate between subjects because the decision making or flow of information gets accomplished as one-way. Especially, because the curtain wall designing accomplished in the architectural design process gets performed without reflecting the engineering technology, it causes many problems in the design phase such as change of design or delay of decision making. In order to make an improvement on such problem, it is estimated that the existing one-way designing can be improved into the one based on cooperation by enabling the exchange of decision making details between concerned parties in the curtain wall design phase in this study and ultimately proposes a curtain wall design management system which enables generation and alteration of information on curtain wall products, information gathering and sharing of information, etc by materializing a design system of simultaneous engineering concept.
\end{abstract}

Keywords: Curtain wall design management system, process model, product model

\section{Introduction}

\subsection{Background and Purpose of Study}

The current curtain wall design process of Korea can be mainly divided into Basic DWG Phase performed at an architectural firm and Shop DWG phase performed at a curtain wall specialized firm. Because the designing from Basic DWG phase to Shop DWG phase gets performed as outcome centered for such work, a designing outcome in which the decision making or information has no consideration for follow-up phases gets produced due to another process. The designing of curtain walls must be accomplished by designing and engineering factors and many problems such as changed operation or delay of decision making due to the change are created in the follow-up phase because there are many cases of designing getting performed without considering the engineering factors in the initial Basic DWG phase. Therefore, this study sets the purpose as proposing a curtain wall design management system that can support an effective information sharing or decision making between two parties from the initial phase of designing.

\subsection{Method and Extent of Study}

In this study, the curtain wall information was classified into planning information such as planning and method of designing, the curtain wall process information and elements or required performance making up curtain wall materials containing performance information and the curtain wall product information dealing with properties of curtain wall itself such as blueprint or instructions expressing them. In order to present effective curtain wall design management system, the study has bee performed with methods of 1)Analysis and improvement of curtain wall process, 2)building curtain wall product model and 3)presenting curtain wall design management system which contains improved process and product information. Also, support and management of curtain wall performance decisions at the engineering aspect in which architect and curtain wall designer must make decisions on main targets for management by cooperation has been set as the key method for development to perform the study. 


\section{The Analysis of Curtain Wall Process}

\subsection{The As-Is Analysis of Design Phase}

In order to get the grasp on As-Is of design phase, the problems of curtain wall construction were recognized through research of books and interviews with specialists, the flow of work by each subjects of curtain wall designing and the flow of information at each phase has been found out through an interview with specialist and the performed modeling like figure 1 . The left is Basic DWG phase and the right is Shop DWG phase.
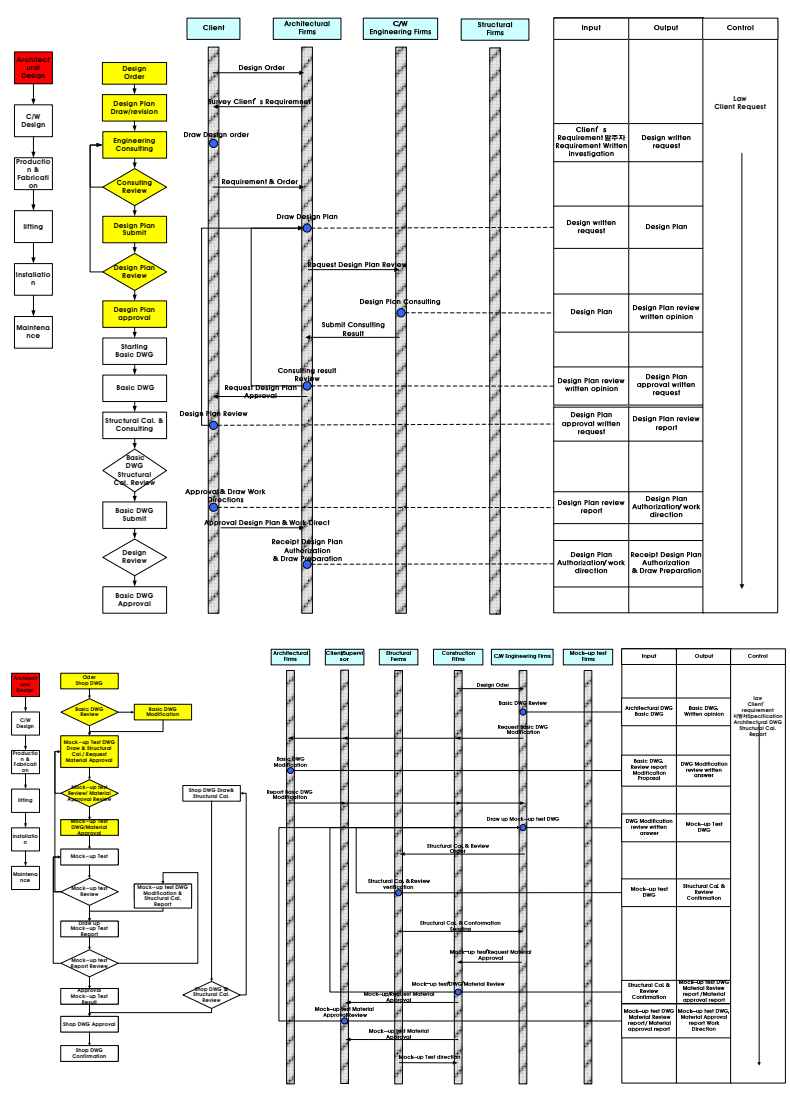

Figure 1 As-Is model of Basic Design Phase

By investigating above design process and recognizing the problems, the improvement factors have been derived. The problems, waste factors and each cause were analyzed by arranging the details as excessive designing sketch, standby, excessive exchange, inappropriate process, re-designing, errors in books and unnecessary stocks with 7 waste viewpoints of Muda. When we take a look at main cause of arranged problem factors, 1) Designing that hasn't considered engineering by two parties 2) lack of communication and information gathering between subjects and 3) insufficient design management system have been recognized as main causes while it has been analyzed that problems like delay of decision making and frequent change of designing in each phase or lowered quality of designing were being created.
In order to solve analyzed problems and causes, I have chosen 3 main solutions of

1) Improvement of process and delivering information, 2) preparation of a plan to establish reference information and 3) improvement on information delivery tool

As main details, the necessity of definition system for each required performance, the necessity of definite planning phase on curtain wall design and Mock-up, the necessity of negotiating process between building owner, planner and curtain wall designer, building a Web-based system that can be shared between all subjects and building a Problem-Alternative-Solution based information management system, etc were set as To-Be method.

figure 2 is a To-Be model in which the process has been improved so that information delivery method between each subject can be improved and establish a negotiation system between subjects based on a system which is under development.
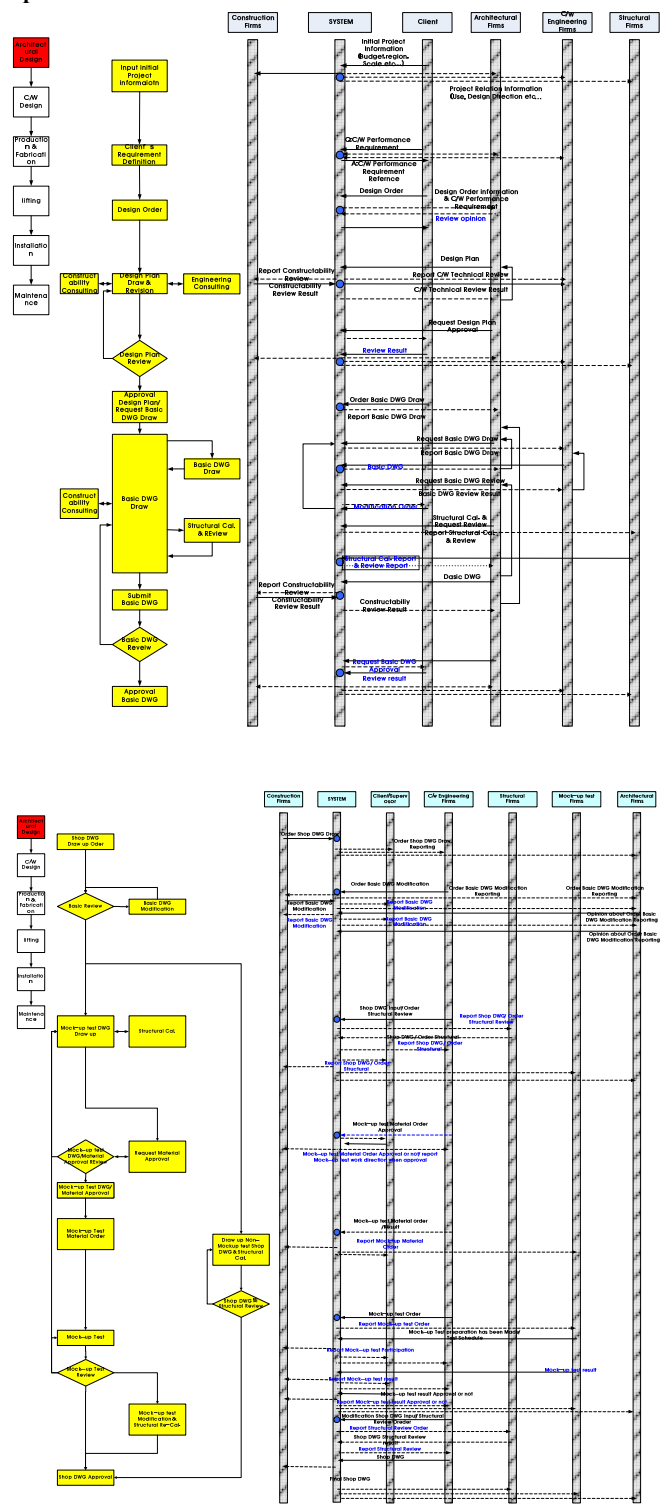

Figure 2 To-Be model of Basic Design Phase

\subsection{The To-Be Model of Design Phase}


Although the To-Be Model gets performed by same order as As-Is in the aspect of work process, it has been made so that overlaps, omissions and errors of documents can be solved in the aspects of information and work by sharing the document based process which was an existing information delivering method using the system, presented so that the lack of specialty and delay in decision making that were the problems of existing design phase could be solved and considerations were made so that prompt and smooth decision making can be accomplished in case there are any changes through monitoring this information by all related parties.

\section{Curtain Wall Product Model}

The product model sets its purpose as the exchange of information between subjects by performing modeling based on data related to outcome. In this study, the product modeling was done on document based blueprint, standard (law, provisions, ordinances, etc) and instruction along with design standard and performance of materials that must be obtained through communications between subjects. Information such as blueprint, document and schedule, etc were arranged with information obtained through process model analysis and the product information related to design standard or material's performance has been analyzed based on curtain wall standard and special instructions of $\mathrm{OO}$ project.

The figure 3 below a Tree-view diagram of items combined with same provisions by analyzing curtain wall standard and special instructions of $\mathrm{OO}$ project.

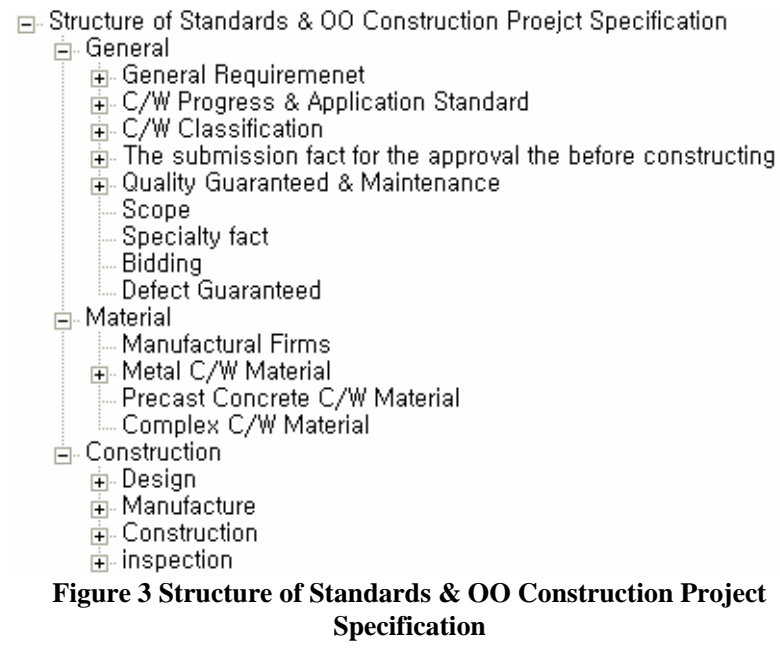

The details contained in curtain wall specifications can be divided into explanation of specifications itself and general details explaining contracting related to projects, items related to used materials, curtain wall design standards, construction, methods and standards related to inspection and the section showing special details of construction. The product model is proposed as figure 4 below based on curtain wall related information and the details of analyzed specification in the process model.

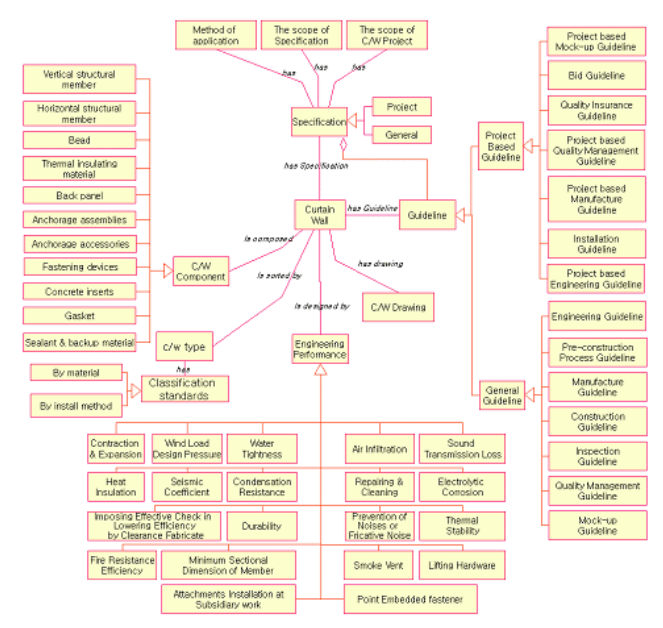

Figure 4 C/W Product Model

\section{The Proposal of Curtain Wall Design Management System}

\subsection{The Method for Development of Curtain Wall Design} Management System

The system proposed in this study is developed with Problem-Alternative-Solution (hereinafter referred to as PAS) concept. The PAS concept has been proposed to improve connectivity with existing PMI (Project Management information System) and KMS (Knowledge Management System) and to support decision making of project in concern. The outcome centered data, blueprint, documents, schedule management, etc were focused on effective management of existing PMIS management method and composed in connection with KMS and PMS concepts in engineering aspect and determination of performance section in which decision making by subjects is required

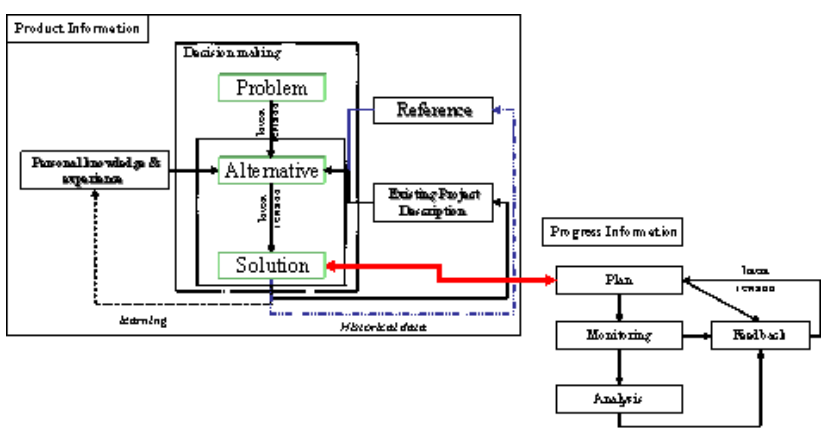

Figure 5 Concept of Information Model

Figure 5 shows information model of PAS concept proposed in this study. In the decision making of performance, the problem which is the subject for decision and the solution which is the result of that decision exist. There are many plans in this process and the most appropriate item among these plans a gets determined as the solution by considering personal knowledge and experience as well as the situation of project in progress among referred 
information. This determined solution can also be used in decision making of future projects by being made into database in the system. Figure 6 show performance section in which decision making model.

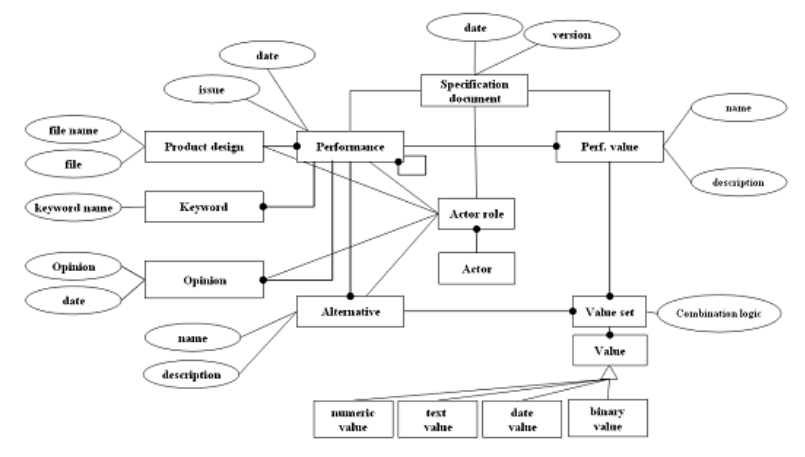

Figure 6 Performance Information Model

\subsection{The Function of System}

The function of system was mainly divided into 1) curtain wall design management which manages the progress and related documents of project in concern, 2) performance and design standard management that can support the preparation their details into specifications in concern and 3) Mock-up test management. Figure 7 is the arrangement of system's functions in a form of tree.

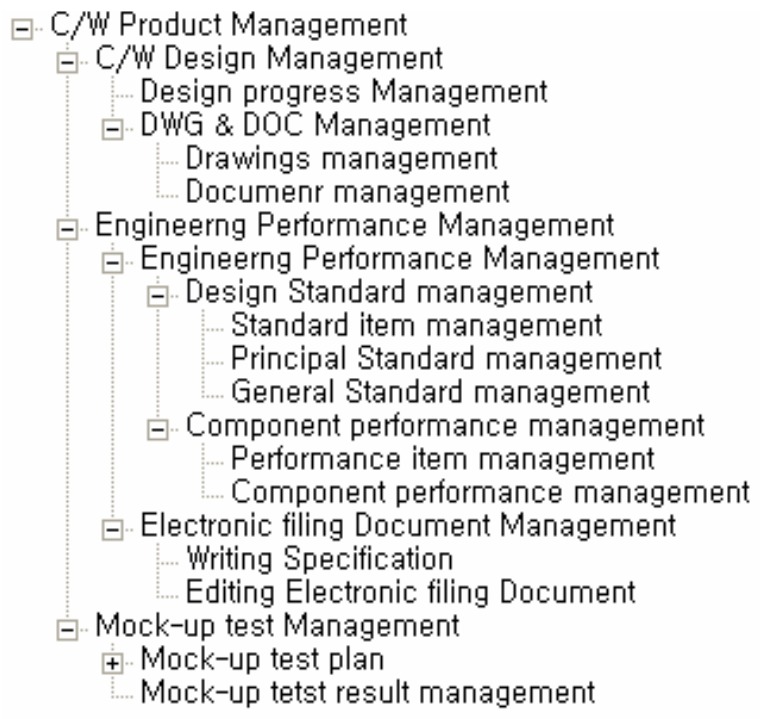

Figure 7 System's Function

1) Curtain Wall Design Management

The main functions of curtain wall design management are design progress management and document (blueprint and various documents) management. The progress management was made so that the progress by each task in concern could be checked by inputting planning date and completion date while the schedule inputted as viewer function can be indicated in a bar chart format. In case of the document management function, the functions from existing PMIS have been imported.
2) Performance and Design Standard Management

The performance and design standard management that are main subjects for development in this study has been made so that decision making items are arranged by key words and made so that it can perform the functions of solution appropriateness validation and support of decision by managing alternative and reference by decision making items. Also, this information was made so that it can support decision making using alternative and reference again in future projects by being accumulated as DB. The electronic document management is a function in which the determined design standard and performance of material can be used directly in preparing specifications and made so that specification can be prepared on the web in the structure of specifications arranged in figure 3.

\section{3) Mock-up test Management}

The Mock-up test management was made so that it can be managed by inputting schedule function proposed at To-Be proposal and made so that spec, allowable, remark and methods, etc can be managed by inputting additional test item management functions.

\section{Conclusion}

This study has proposed the process model which improves the flow of information being generated and materialized in curtain wall design phases as well as the curtain wall design management system that can effectively use and manage decision making information. The results of this study are the as follows.

1) The model to get the grasp on flow of information by each subject has been expressed and analyzed, problems and waste factors have been derived and the main problems were recognized as the designing in which engineering of each subject isn't considered, lack of communication and information gathering as well as inadequate design management system.

2) The plan for improvement has been presented as improvement of process, building system for reference information and the improvement of information delivering tool for the problems derived.

3) The product model which sets the purpose as exchange of information in a curtain wall design management system by each subject has been proposed by analyzing product information of curtain wall

4) The decision making related to performance between the subjects of designing and an information model has been proposed based on PAS concept.

5) A curtain wall design management system that can effectively manage documentary information created in the design phase and support decision making by each subject has been proposed.

This research has made a proposal on main functions of design management system that are applicable at the curtain wall design phase and this design management system is being studies as a part of integrated curtain wall 
management system. A more specific definition of system performance is necessary in the future and a system based on key functions proposed in this study is under development.

\section{ACKNOWLEDGEMENTS}

This research (Grant No. 2003 R\&D A01-03) is financially supported by the Ministry of Construction and Transportation of the Korea government, Dealim Industrial Co, Better Living Space Co., and Doaltech Co. This work is also supported by Brain Korea 21 Project

\section{REFERENCES}

[1] Jae-Youl Chun, A Study on Selection Algorithm for the Propriety Building Component through Collaborative Decision Making in Architectural Design Phase, Architectural Institute of Korea, 2003,11

[2] Sueng-Jun Oh, A Study on the Application of Support Model for Collaborative Decision Making in Architectural Design Phase, Architectural Institute of Korea, 2004, 8

[3] Ju-Han Lee, A Study on Structuring Information Management System for Architectural Design Architectural Institute of Korea, 2001, 10

[4] Joo-Young Lee, A Study on XML based representation of the architectural design information in AEC areas, Architectural Institute of Korea, 2003, 6

[5] Auca Tuzmen, A distributed process management environment for collaborative building design, Arizona State University, 2001

[6] Khemlani, Lachmi S, Integrated building representation for computer-aided multi-disciplinary design, University of California, Berkeley, 2000

[7] Kyoon-Tai Kim, A Web-Based Writing Support System for Construction Project Specification, Architectural Institute of Korea, 2002, 7

[8] Jae-Hyun Kim, A Study on Creating and Searching Architectural Specification Information using Web Technology, Architectural Institute of Korea, 2001, 4 